Estudios deDerecho

Fundada en 1912
UNIVERSIDAD DE ANTIOQUIA 


\title{
Decisión judicial y situación carcelaria en Colombia: la encrucijada de los fallos estructurales*
}

\author{
Diego Mauricio Olarte Rincón**
}

\begin{abstract}
Resumen
La situación de las cárceles en Colombia regresó, después de quince años, al análisis estructural de la Corte Constitucional. En esta ocasión, tras dos nuevos fallos de estado de cosas inconstitucional, la Corte resolvió reenfocar el entendimiento del problema carcelario y profirió órdenes de diversa índole para conjurar el déficit de derechos de las personas privadas de la libertad. Pese a estos esfuerzos de la Corte, sus fallos parecen no haber tenido éxito en la protección de los derechos de las personas privadas de la libertad, enfrentándose así a una encrucijada que impide su cumplimiento. Este artículo de reflexión analiza estas decisiones a la luz de teorías de carácter general sobre los fallos estructurales y en particular sobre aquellas relativas al sistema penitenciario y carcelario para describir cómo se expresa dicha encrucijada y se propone un remedio judicial que, sin ser susceptible de álgidos debates, puede resulta en una medida efectiva para la protección inmediata de la población privada de la libertad. Palabras clave: sistema penitenciario y carcelario; crisis carcelaria; estado de cosas inconstitucional; fallos estructurales.
\end{abstract}

\section{Judicial decision and prison situation in Colombia: The crossroads of structural decisions}

\begin{abstract}
After fifteen years, the prison system's situation in Colombia returned to its structural analysis by the Constitutional Court. On this occasion, after two new decisions regarding the unconstitutional state of affairs of Colombian prisons, the Court determined to refocus the understanding of the problem and issued orders of various kinds to avert the deficit of rights of persons deprived of liberty. Despite the numerous efforts by the Court, its judgments seem to have failed in the protection of the rights of imprisoned people, facing a crossroads that prevent the fulfillment of judicial decisions. This reflection paper analyzes these decisions in the light of general theories about structural decisions and, in particular, those related to the penitentiary and prison system. It aims to describe how the crossroads are expressed and it comes up with a judicial remedy to be debated, which can be considered a more efficient measure to ensure the immediate protection of people deprived of liberty.

Keywords: penitentiary and prison system; prison crisis; unconstitutional state of affairs in prisons; structural decisions.

\section{Decisão judicial e situação carcerária na Colômbia: a encruzilhada das decisões estruturais}

\section{Resumo}

A situação das prisões na Colômbia voltou, depois de quinze anos, à análise estrutural da Corte Constitucional. Nesta ocasião, depois de duas novas decisões de Estado de Coisas Inconstitucional, a Corte resolveu focar-se novamente no entendimento do problema carcerário e proferiu ordens de diversas índoles para impedir o déficit de direitos dos detentos. Apesar desses esforços da Corte, suas decisões aparentemente não obtivem sucesso na proteção dos direitos dos detentos, enfrentando-se assim a uma encruzilhada que impede seu cumprimento. Este artigo de reflexão analisa estas decisões à luz de teorias de caráter geral sobre as decisões estruturais e particularmente sobre aquelas relativas ao sistema penitenciário e carcerário para descobrir como se expressa tal encruzilhada e se propõe uma solução judicial que, sem ser susceptível a debates intensos, pode dar como resultado uma medida efetiva para a proteção imediata da população detenta.

Palavras-chave: sistema penitenciário e carcerário; crise carcerária; Estado de Coisas Inconstitucional; decisões estruturais.

* Artículo de reflexión derivado de investigación. Investigación terminada en julio de 2020.

** Abogado y magíster en Derecho de la Universidad de los Andes. Máster en Criminología y Ejecución Penal de la Universidad Pompeu Fabra, España. Correo electrónico: diegomolarte@gmail.com. ORCID: 0000-0003-4329-9797.

Cómo citar este artículo: Olarte Rincón, D. M. (2021). Decisión judicial y situación carcelaria en Colombia: la encrucijada de los fallos estructurales. Estudios de Derecho, 78 (171), 223-244

DOI: 10.17533/udea.esde.v78n171a09

Fecha de recepción: 17/07/2020 Fecha de aceptación: 19/10/2020 


\section{Decisión judicial y situación carcelaria en Colombia: la encrucijada de los fallos estructurales}

\section{Introducción}

La prisión en Colombia es sinónimo de hacinamiento y violencia ${ }^{1}$. Desde los años noventa, el país ha experimentado un drama humanitario en sus cárceles por cuenta de la sobrepoblación de reclusos, llegando a cifras alarmantes en los últimos años que registraron un hacinamiento por encima del 50 por ciento ${ }^{2}$. Esta constante supone una insuficiencia persistente: escasez de camastros ${ }^{3}$, de baños, de plazas para programas de resocialización, de citas médicas, de personal y vehículos para hacer remisiones de reclusos a diligencias judiciales, entre otros. A su vez, esta limitada oferta de bienes y servicios, en un contexto de alta demanda de personas, desata un conflicto permanente que enfrenta a los reclusos y anima todo tipo de disputas (Ariza, 2011).

Una situación de esta dimensión tan escandalosa ha merecido la atención de la Corte Constitucional, tribunal que en diversas ocasiones ha buscado dar

1 Ariza (2010) advierte que esta realidad no solo se presenta en el contexto colombiano: “[d]esafortunadamente, la diferencia entre las 'fallas' de los sistemas penitenciarios latinoamericanos tan sólo es de grado: algunos son más violentos, otros sufren menos hacinamiento, pero todos ejercen violencia y funcionan por encima de su capacidad. Las muertes por motines, incendios o arbitrariedad son una constante a lo largo de los patios de las prisiones latinoamericanas" (p. 31). Además, al igual que en Colombia, el hacinamiento es detectado por las autoridades con relevancia en la política penitenciaria de América Latina como uno de los principales problemas a enfrentar (Carranza, 2009). El hacinamiento en algunos países de la región es el siguiente: Brasil (70 \%), Perú (141\%), Chile (0,4 \%), Argentina (22\%), Bolivia (263 \%), Ecuador (33 \%), y Venezuela (54 \%) (World Prison Brief, 2020).

2 Desde 2012, el hacinamiento ha oscilado entre el 44 \% y el 55 \%. Estas cifras tuvieron un descenso atípico en 2020 por la pandemia por COVID-19 que llevó al hacinamiento al $24 \%$ (Instituto Nacional Penitenciario y Carcelario [INPEC], 2020), en medio de una coyuntura en la que se cerraron los penales y se produjo una mayor extensión del hacinamiento a los centros de detención transitoria. Desde hace algunos años, las principales ciudades del país se han visto resentidas por el hacinamiento carcelario trasladado a los centros de detención transitoria. No obstante, durante la pandemia este hacinamiento llegó a cifras históricas de alrededor de 12.000 personas (MinJusticia, 2020).

3 ¿En dónde duerme cada noche el excedente de personas, que a fecha de diciembre de 2019 ascendió a 42.822 individuos? En colchonetas ubicadas en los suelos de celdas, pasillos y baños, en hamacas o, incluso, en los mismos camastros, pero en turnos diurnos, renunciando con esto a participar de la oferta de programas de resocialización. 
órdenes de tipo estructural a las autoridades concernidas para que se mejoren las condiciones de reclusión en las cárceles del país.

En efecto, en 1998, la Corte Constitucional colombiana declaró el primer estado de cosas inconstitucional (ECI) en las prisiones del país ante la masiva vulneración de múltiples derechos de la población reclusa (Corte Constitucional, Sentencia T-153 de 1998). Este llamado, impulsó la creación de nuevas cárceles y, por unos años, se logró reducir el índice de hacinamiento que mereció la sentencia de la Corte.

Sin embargo, tiempo después, las alarmas volvieron a encenderse. Pese a que la oferta de cupos carcelarios creció entre 1998 y 2013 un 129 \%, pasando de 33.119 cupos a $76.066^{4}$, la población recluida en las cárceles del país aumentó a 120.032, pasando el hacinamiento de un $31 \%$ en 1998, al $55 \%$. Producto de este claro aumento de personas privadas de la libertad que derivó en que se recrudecieran las condiciones de habitabilidad de los reclusos en las cárceles, la Corte Constitucional, en 2015 (Sentencia T-388 de 2013 ) y 2016 (Sentencia T-762 de 2015), profirió dos nuevas sentencias que declararon otra vez el ECI en las prisiones y fijó nuevas órdenes de carácter estructural para conjurar el déficit de derechos de los reclusos.

A grandes rasgos, a diferencia del primer ECI en el que principalmente se ordenó la ampliación del sistema penitenciario a través de la construcción de más cupos penitenciarios para atender la alta demanda de personas privadas de la libertad (Ariza, 2015), en los últimos dos la Corte reformuló el planteamiento, evidenciando que el asunto carcelario requiere ser entendido desde una óptica más amplia y señalando que la política criminal en su conjunto debería ser revisada para depurar la crisis (Ariza y Torres, 2019; Moscoso Sepúlveda, 2017; Ramírez, Gómez, Medina, Farfán y Moncada, 2019).

Algunos autores han hecho revisiones y análisis acerca de las intervenciones judiciales de la Corte en las que profiere fallos estructurales a manera de ECI. Si bien estos trabajos suelen abarcar la pregunta por la legitimidad de la Corte Constitucional para exigir a los hacedores de políticas públicas (usualmente el Congreso y los gobiernos) ajustes o construcción de las mismas ${ }^{6}$, algunos otros

4 Estos cupos carcelarios materializaron los documentos Conpes 3086 de 2000; 3277 de 2004; 3412 de 2006; y 3575 de 2009.

5 Mientras que el año 1998 la capacidad de las cárceles fue de 33.009 internos y la población 43.259, en 2013 la capacidad fue de 75.797 cupos y los internos 117.987 (INPEC, 2020).

6 Henao Pérez (2013) o Cepeda (2007) han propendido por destacar la necesidad de intervención del juez constitucional en las situaciones de vulneración masiva y sistemática de derechos fundamentales que soportan la declaración de un ECI. De acuerdo con Henao Pérez (2007), la inacción de las autoridades legislativas y administrativas para garantizar derechos fundamentales de grupos poblacionales, sumado al mandato otorgado de preservar la Constitución Política y a los compromisos internacionales que ha suscrito el Estado colombiano de materializar derechos, exigen que la Corte intervenga en políticas públicas para lograr materializar el goce efectivo de los derechos (pp. 74-77). En el mismo 
estudios se han concentrado en la fase de implementación o cumplimiento de estas decisiones. En este último espectro se encuentran autores como Rodríguez Garavito y Rodríguez Franco (2010, 2015), quienes procuran construir una teoría que permita leer con las mismas características cualquier fallo estructural de la Corte. Otros estudian principalmente la injerencia de la Corte en las cárceles para mostrar las características especiales que tiene esta temática desde el punto de vista de las particularidades de la institución de la prisión (Ariza, 2010, 2015).

En este contexto, el propósito de este escrito es analizar estas decisiones judiciales de tipo estructural, específicamente las más recientes (Sentencias T-388 de 2013 y T-762 de 2015) a la luz del marco conceptual general con el que se ha analizado el ECI de cárceles, para evidenciar, en la fase de cumplimiento de estos fallos, que las órdenes emitidas se enfrentan a una encrucijada en razón de la diversidad de resistencias que se manifiestan y que dificultan la garantía de los derechos de las personas privadas de la libertad, por lo que se debería buscar un remedio judicial más efectivo que conjure el déficit de derechos.

Para hacer esto, presento, en la segunda parte de este texto, el marco teórico sobre el cual me apoyé para descifrar algunos elementos con los que deben ser analizados los ECI en materia carcelaria. Posteriormente, en la tercera parte, realizo un análisis de los fallos estructurales de prisiones sobre la base de los elementos que aporta el marco teórico que utilizo, para presentar la encrucijada a la que se ve enfrentado el cumplimiento del ECI y, con esto, el goce de derechos de la población privada de la libertad. En la cuarta parte propongo un remedio judicial que puede resultar más efectivo para la garantía de los derechos de los reclusos. Y, finalmente, en la quinta parte, presento unas conclusiones a partir de dicho análisis.

\section{La intervención judicial estructural en fase de cumplimiento}

Rodríguez Garavito y Rodríguez Franco $(2010,2015)$ son los exponentes principales de la literatura académica en Colombia que procura explicar los elementos configurativos de la eficacia de los fallos estructurales. Además de centrar su análisis en los múltiples efectos que se desprenden de estos, identifican como elemento central de una correcta implementación de estas decisiones el carácter dialógico que se desarrolla entre el juez, las partes y los múltiples actores de interés que gravitan alrededor de la problemática que pretende ser conjurada. A su

sentido, Cepeda (2007) exalta el hecho de que la intervención es inevitable, pero se realiza desde la función judicial, es decir, cuando las entidades encargadas de formular las políticas públicas no han logrado previamente conseguir la satisfacción de los derechos de las personas (pp. 527-528). Rodríguez Garavito y Rodríguez Franco (2015) también dan respuestas sobre la legitimidad de estos fallos judiciales, pero desde el punto de vista del enfoque dialógico de estas decisiones estructurales. 
vez, de acuerdo con estos autores (2010), las decisiones judiciales estructurales con enfoque dialógico se caracterizan por sacudir a la burocracia estatal para que pase del bloqueo institucional en el que se encuentra a la búsqueda de medidas tendientes a la satisfacción de los derechos de la población vulnerada. Recientemente, Rodríguez Garavito y Rodríguez Franco (2015) han señalado que son al menos tres los tipos de bloqueo institucional que procuran ser superados a través de una decisión estructural: (i) las fallas burocráticas; (ii) la falta de capacidades; y (iii) los intereses políticos.

Por un lado, está el bloqueo producto de las fallas burocráticas de las entidades públicas que impiden una coordinación interinstitucional adecuada entre ellas para formular e implementar políticas. En este punto se podría indicar que las distintas agendas de las instituciones no suelen coincidir en los mismos propósitos, lo que impide avanzar en la consecución de metas y resultados que se traduzcan en garantía de derechos de los ciudadanos. Un segundo bloqueo se manifiesta por cuenta de la falta de capacidades de las instituciones para poder atender su misionalidad. Al respecto, se debe considerar que algunos sectores de la burocracia estatal del país adolecen de los conocimientos especializados y destreza institucional requerida para proveer de manera eficiente todos los servicios que se le encargan. A su turno, un tercer bloqueo institucional que se advierte tiene que ver con intereses políticos por parte de agencias del Estado o de particulares incidentes en las políticas públicas que capturan "el proceso político o la política pública sobre un tema, en detrimento de los intereses o derechos de grupos menos poderosos" (Rodríguez Garavito y Rodríguez Franco, 2015, p. 231)7 . Aun cuando estos elementos han sido teorizados para explicar la decisión estructural y el seguimiento realizado por la Corte Constitucional al ECI de desplazamiento forzado en Colombia (Sentencia T-025 de 2004), estos autores aducen que estos elementos son característicos de todas las decisiones de tipo estructural que profieren las autoridades judiciales en las que se observan rasgos dialógicos. Como quiera que este rasgo es observado en las sentencias de ECI recientes de cárceles, más adelante serán analizados los elementos destacados por estos autores.

7 Rodríguez Garavito y Rodríguez Franco (2015) reconocen que en estas materias son escasos los trabajos desarrollados para ilustrar este último bloqueo de tipo político: “[c]omo se ha señalado, nuestra hipótesis con respecto al mayor impacto del activismo dialógico se limita a los elementos controlados por el tribunal que tienen influencia en el efecto de las mencionadas sentencias y otras decisiones activistas. En la práctica, hay factores externos, desde la reacción de las partes afectadas en los sectores públicos o privados al grado de apoyo de los medios de comunicación y las organizaciones de la sociedad civil, que influencian por igual los efectos de las intervenciones judiciales. Por ejemplo, la T-025 y la T-760 difieren en un aspecto importante: mientras que en el primero de los casos la CCC (Corte Constitucional de Colombia) no enfrentó resistencia por parte de intereses creados fuera del Estado, en la segunda tuvo que afrontar una considerable resistencia por parte de los beneficiarios de un sistema disfuncional, entre los cuales estaban prestadores privados de servicios de salud y empresas farmacéuticas que explotaron los vacíos regulatorios del sistema. A diferencia del caso "TAC" sudafricano sobre el derecho a la salud, la CCC no podía apoyarse en un fuerte movimiento social capaz de contrarrestar esa resistencia. Se necesitan investigaciones adicionales para desentrañar la interacción entre los factores controlados por el tribunal y los factores externos que afectan el impacto de las intervenciones judiciales" (p. 224). 
Por su parte, Ariza $(2010,2015)$ analiza la injerencia de las decisiones estructurales de la Corte Constitucional al interior de la institución penitenciaria específicamente. De acuerdo con este autor, en el entendido de que la barrera que existe entre los derechos (en abstracto) y las personas vulneradas o marginadas es la falta de políticas públicas que materialicen el goce de los derechos económicos, sociales y culturales (DESC), la Corte suele exigir en este tipo de fallos la formulación de las mismas. Y como quiera que la construcción de dichas políticas públicas, o su implementación, no suele darse de forma inmediata, dada la complejidad de los asuntos que se pretenden resolver (de carácter estructural), una característica principal de estos fallos es su progresividad.

Así, se entiende que las respuestas institucionales no brindarán resultados inmediatos de satisfacción de derechos, pero sí deben estructurarse los planes y programas (las políticas públicas) que tengan como meta dicha satisfacción.

Sin embargo, como lo explica Ariza (2015), tratándose del déficit de derechos de la población reclusa, dicha progresividad no se puede pregonar, en tanto la relación de especial sujeción del preso frente al Estado crea obligaciones inmediatas en cabeza de este último para poder brindarle aquellos servicios que la privación de la libertad le impide autogestionarse o autoproveerse. Un caso notorio de este planteamiento, es el derecho de todos los presos a tener condiciones dignas de habitabilidad en las prisiones. En tanto los internos no cuentan con la capacidad para proveerse un espacio digno de reclusión, es obligación del Estado brindar lugares de reclusión que respeten la dignidad de los privados de la libertad (ibíd., 2010).

A su vez, otro elemento que considera Ariza (2015) necesario para estudiar la intervención judicial de la Corte en las cárceles, tiene que ver con la forma como se construye el caso que se pretende resolver. Al respecto, señala que los remedios que suelen proferirse en un fallo estructural están en estrecha relación con la forma como la Corte decide abordar el caso de violación de derechos ("el debate jurídico específico") que estudia (p. 191). A su juicio, la fase de implementación de una decisión de tipo estructural está directamente asociada con la construcción del caso que hace la autoridad judicial, en tanto de esta construcción dependen los remedios que se impartan. En razón a lo anterior, y a que, como ya se dijo, una particularidad de las personas privadas de la libertad es que se encuentran en una relación de especial sujeción con el Estado, Ariza (2015) cuestiona los análisis que abordan toda problemática masiva de derechos desde el discurso de reforma estructural para la protección de DESC, toda vez que no permiten entrever las particularidades específicas que cada caso puede suponer:

Un problema de los análisis basados en la definición de los casos con base en el discurso jurídico sobre los DESC y su correlato de la reforma estructural es que agrupa las situaciones en una misma categoría analítica, sin prestar la suficiente atención a la especificidad de cada 
intervención. Así, el caso de una persona desplazada forzosamente sería equiparable según la doctrina del ECI al de una persona privada de la libertad en condiciones infrahumanas. (...) [N]o debería perderse de vista que la intervención en el campo penitenciario supone intereses, actores y valores propios, que participan dentro de un campo posible de instituciones y doctrinas jurídicas propias, a pesar de los rasgos que comparten con otros casos interpretados desde la óptica del ECI. Incluso la intervención judicial en el campo penitenciario supone una pluralidad de posiciones sobre la forma como se construye el caso, el papel de la judicatura en este proceso, la definición de los remedios y su posterior puesta en marcha. (Ariza, 2015, p. 192)

Como se observa, estos actores han decantado algunos elementos que deben ser tenidos en cuenta para analizar los tres fallos estructurales que ha proferido la Corte Constitucional en materia carcelaria. Los elementos aquí presentados son: (i) la presencia de bloqueos institucionales de tipo burocrático, de capacidades y político que pretenden ser superados; (ii) el carácter inmediato de la protección de los derechos de las personas privadas de la libertad, por tratarse de un asunto en el que existe una relación de especial sujeción del preso frente al Estado; y (iii) la incidencia de la construcción del caso con relación al tipo de remedios (u órdenes) proferidas que incide en el eventual impacto de los fallos estructurales. A continuación, analizo estos elementos a la luz de los dos últimos fallos estructurales del ECI en el sistema penitenciario y carcelario.

\section{Los ECI de cárceles en la encrucijada de la intervención judicial estructural}

\subsection{Bloqueos persistentes}

Como muestran Rodríguez Garavito y Rodríguez Franco (2015), los bloqueos institucionales que procuran ser desatascados con una decisión estructural de ECI son de tres tipos: políticos, de capacidades y burocráticos. En el ECI de cárceles, infortunadamente, los tres tipos de bloqueos se expresan en perjuicio de los derechos de los privados de la libertad, como quiera que las sentencias de ECI no parecen haber hecho fluir a la burocracia estatal del campo penitenciario para propender resolver sus múltiples fallas.

Bloqueo político persistente. Las órdenes que se rastrean particularmente en las Sentencias T-388 de 2013 y T-762 de 2015 relacionadas con la reducción del encarcelamiento ${ }^{8}$ han mostrado tener un fuerte bloqueo institucional de

8 En particular, se deben considerar las decisiones relacionadas con la aplicación de la regla de equilibrio decreciente, a través de la puesta en marcha de las medidas legislativas y administrativas necesarias para generar un descenso 
tipo político por parte de ciertos actores estratégicos de la política criminal. Las preocupaciones de estos actores relativas al peligro que puede implicar una excarcelación masiva al "relajar las penas impuestas a los delincuentes", siguiendo con ellos, hace necesario reflexionar "si la suerte de los delincuentes es volver a las calles o tener un tratamiento efectivo para no exponer al ciudadano frente a los delitos de seguridad ciudadana".

Si bien el debate de fondo que plantea este tipo de actores pone en contraste los derechos de los privados de la libertad a una vida digna, a la salud, a no recibir tratos inhumanos o degradantes, entre otros, contra una construcción en abstracto de la seguridad de la ciudadanía que estaría siendo vulnerada ante la libertad de estas personas, esta ponderación, cuando menos, desconoce los trabajos que analizan cómo los sectores más vulnerables de la sociedad han vivido un proceso en el que se les ha dejado de ver como sujetos receptores de oferta pública social, al tiempo que se ha venido generando una "hipertrofia del Estado penal" que los ha convertido en delincuentes (Wacquant, 2010) ${ }^{10}$. Además de esto, esa ponderación resulta cuestionable, en la medida que desconoce también que, tarde o temprano, "todos salen de prisión", con lo cual su retraso en salir solo afecta las posibilidades de reinserción de estas personas ${ }^{11}$, a la vez que entorpece la construcción de un derecho penal sustentado en la proporcionalidad estricta que debe vincular a la conducta punible con la sanción a imponer ${ }^{12}$.

De este modo, es posible que las órdenes orientadas a reducir los niveles del encarcelamiento no se vayan a implementar, dejando así sin resolver una de las principales exigencias planteadas por la Corte Constitucional:

El hacinamiento es uno de los problemas que con mayor urgencia requiere atención, por la capacidad de agravar los demás obstáculos y dificultades que enfrenta el Sistema, y por hacer más difícil y gravosa cualquier opción de solución. El hacinamiento es un problema que no sólo se resuelve con más cárceles (más cupos para privar a

gradual de la población privada de la libertad (Sentencia T-388 de 2013) y las encaminadas a exigir la adopción del estándar constitucional que debe cumplir una política criminal respetuosa de los derechos humanos, que involucra la satisfacción de principios del derecho penal como el de su estricta necesidad, derecho penal mínimo, proporcionalidad de la sanción, alternatividad al encarcelamiento, entre otros (Sentencia T-762 de 2015).

9 Algunos congresistas y la Fiscalía General de la Nación (con una resonancia mayor) han hecho públicas estas preocupaciones (Noticiero CM\&, 2017; Noticias RPTV, 2016).

10 Esto da pie a revisar el debate propuesto por Garland (2012) o Zaffaroni (2013), y en el contexto local Iturralde (2007, 2010a y 2010b) con relación a la construcción de una cultura del control que sobrepone los discursos de seguridad (nacional o ciudadana) por encima de la libertad, en el marco de los estados neoliberales.

11 "But they all come back" ["pero todos regresan"] es la frase original y popular con la que se cuestiona el endurecimiento punitivo, con el resultado perverso de llevar a cabo liberaciones de reclusos que, por sus altas condenas, tienen mayores dificultades para reincorporarse a la sociedad una vez recobran su libertad (Travis, 2000).

12 Al respecto, vale la pena revisar lo propuesto recientemente por Cita y González (2017) relacionado con la incidencia de la seguridad ciudadana con ocasión a la desproporcionalidad de las penas en la legislación colombiana. 
más personas de la libertad); también se debe enfrentar con menos cárcel, esto es, con un menor uso del castigo penal, como herramienta de control social. (Corte Constitucional, Sentencia T-388 de 2013)

Bloqueos persistentes por falta de capacidades. La expectativa de concretar las múltiples mejoras requeridas en el campo penitenciario (adecuaciones de la infraestructura, mejores procesos de resocialización, prestación efectiva de servicios de salud, garantía de servicios públicos esenciales, entre otros ${ }^{13}$ ), señaladas en los últimos ECI de cárceles, también están en entredicho a propósito del evidente bloqueo que persiste con relación a la falta de capacidades de las instituciones principales del sistema penitenciario y carcelario: el INPEC, responsable de la custodia y vigilancia de los reclusos y la Unidad de Servicios Penitenciarios y Carcelarios (USPEC), encargada de proveer los servicios y la infraestructura del sistema penitenciario.

En cuanto al INPEC, pese a los esfuerzos del gobierno para reducir el déficit de personal en cerca de 16.000 personas $^{14}$, sus intenciones se quedan rezagadas. Si bien en una reciente ley de adición presupuestal el gobierno nacional inyectó recursos por 70.000 millones de pesos para cubrir cerca de 1.000 cargos desprovistos en la entidad (Ley 1837 de 2017), y pese a que la Ley 1896 de 2018 buscó la creación de 2.700 nuevos cargos en el INPEC durante las vigencias 2019 y 2020 (Congreso de la República, PL 026/17 Cámara), estas acciones no logran suplir el déficit de personal (seguirían haciendo falta al menos otros 12.000 nuevos cargos). Y si bien, el propio gobierno argumentó en su momento que la cifra de déficit de personal calculada en 16.000 funcionarios tenía que ser reconsiderada y reducida, pues otras medidas de política criminal también se estaban procurando para reducir el número de privados de la libertad (lo que implicaría la reducción de la necesidad de personal) ${ }^{15}$, lo cierto es que, como aquí se ha detallado, esas otras acciones han enfrentado otras resistencias o bloqueos que las han dejado prácticamente irrealizables.

La ausencia de personal suficiente en la institución encargada de ejecutar la medida de aseguramiento intramural y la ejecución de la pena supone para el Estado tener que cumplir una función especializada y, en algunos casos, de alto

13 El Auto 121 de 2018 identificó seis dimensiones de la vida en prisión respecto de los cuales se va a desarrollar la estrategia de seguimiento basada en indicadores de derechos. Estas dimensiones son: (i) resocialización; (ii) salud; (iii) infraestructura; (iv) servicios públicos; (v) alimentación; y (vi) acceso a la administración pública y de justicia.

14 De acuerdo con la exposición de motivos del proyecto de ley 026 de 2017 Cámara, posteriormente convertido en la Ley 1896 de 2018, que procuraba y materializó una excepción a la imposibilidad de aumentar las plantas de personal con el objetivo de acrecentar el personal de guardia del INPEC, el déficit de personal del INPEC se calcula en 16.000 funcionarios.

15 En la exposición de motivos del proyecto de ley 026/17 Cámara, el gobierno sustentó que no es necesario un aumento de 16.000 funcionarios en el INPEC teniendo en cuenta que se están tomando medidas de política criminal, referenciando explícitamente que el éxito en el trámite legislativo del proyecto de ley 014 de 2017, construido por el Consejo Superior de Política Criminal, redundaría en "una reducción razonable de personas privadas de la libertad ubicadas en centros de reclusión, lo que generará una mejora en la relación guardias-internos en el sistema penitenciario y carcelario" (Congreso de la República, PL 026/17 Cámara). Pese a lo anterior, esta iniciativa legislativa fue archivada con tan solo un debate superado en el Congreso. 
riesgo, sin las garantías suficientes para poder llevar a cabo esta labor de forma adecuada. Por su parte, para los reclusos supone retrasos en la habilitación de plazas de tratamiento penitenciario, en el cómputo de redención de su pena, en las remisiones médicas o judiciales, entre otros. Por lo anterior, en ciertos casos esa incapacidad ha comprometido el control de los centros de reclusión y ha desatado la proliferación de actos de corrupción al interior de las prisiones: la alta demanda de servicios y la escasez de los mismos, hace que la prisión sea un permanente campo de disputa donde reina la ley del más fuerte ${ }^{16}$.

Por su parte, es posible igualmente detectar bloqueos persistentes relativos a la falta de capacidades en la otra entidad central del campo penitenciario, la USPEC. Estos bloqueos se ven reflejados en las decenas de hallazgos que la Contraloría General ha evidenciado respecto del desempeño de esa entidad en la provisión de servicios en los centros de reclusión. Así, se constatan múltiples falencias en el seguimiento a proyectos de mantenimiento o construcción de nuevas cárceles (Contraloría, 2017a), se advierten diversos pronunciamientos sobre la forma inadecuada como se ofrece el servicio de alimentación (Contraloría General de la República, 2019a) y se denuncian fallas en la prestación de los servicios de salud (que involucran personal de salud incompleto en los penales, entrega incompleta de medicamentos a los reclusos, entre otros) (Contraloría, 2017b) ${ }^{17}$. Estas denuncias son especialmente preocupantes en un contexto en el que las condiciones de reclusión de las cárceles del país son contrarias al orden constitucional, lo que exigiría optimizar las inversiones de recursos para garantizar que la provisión de los servicios carcelarios a cargo de la USPEC respete los derechos de la población privada de la libertad y aumenten de vigencia a vigencia.

Bloqueos institucionales persistentes de tipo burocrático. La Sentencia T-762 de 2015 pareció tener un fuerte efecto desbloqueador al interior del gobierno nacional. A raíz de este fallo judicial, la Presidencia de la República lideró por más de un año mesas de discusión con todos los actores del gobierno concernidos para propiciar respuestas estatales del tamaño de la problemática y, en conjunto con la Defensoría del Pueblo y la Procuraduría, lograron que las entidades trabajaran de manera articulada y proactiva ${ }^{18}$. Pese a lo anterior, en los últimos años ese liderazgo se ha diluido, dando paso a reiterados problemas de interacción con algunos actores.

16 Para el efecto, ver el estudio de caso desarrollado por Ariza (2011) en la Cárcel Modelo de Bogotá, en el que describe cómo se configura el orden social en esta prisión.

17 Además, durante las vigencias 2017, 2018 y 2019, la Contraloría ha emitido opinión negativa a los estados financieros de la USPEC (Contraloría General de la República, 2018, 2019b y 2020a). La noticia más reciente sobre USPEC que se registra en el portal web de la Contraloría hace relación a que la USPEC dejó de ejecutar cerca de 45.000 millones de pesos en la vigencia fiscal del 2019 (Contraloría General de la República, 2020b).

18 Asílo reconoció el grupo líder de seguimiento de la sentencia T-762 de 2015 en el segundo informe presentado a la Corte Constitucional (Grupo líder de seguimiento, 2017, p. 151). 
Con todo, incluso en el punto de mayor engranaje institucional, el propio gobierno ${ }^{19}$ sostuvo que un cuello de botella en el cumplimiento de las órdenes era que, si bien este se encontraba comprometido con tener una iniciativa legislativa orientada por el estándar de política criminal construido por la Corte, no podía exigir lo mismo del Congreso, cuya independencia y conformación colegiada lo hacen impredecible:

Persisten la dispersión normativa y el populismo punitivo en atención a la desarticulación entre el Gobierno nacional y el Congreso de la República que además de aprobar o reprobar las propuestas presentadas por el Gobierno en materia de política criminal, también puede presentar sus propios proyectos de ley -no necesariamente alineados con el ejecutivo- lo que genera dispersión normativa y agrava el populismo punitivo que tanto cuestiona la Corte. (Grupo Líder de seguimiento, 2017, p. 88)

Otra manifestación del bloqueo institucional de tipo burocrático ha sido advertida por la Corte Constitucional a través de sus autos de seguimiento y hace referencia a los retrasos en la articulación del Comité interdisciplinario para la estructuración de normas técnicas sobre privación de la libertad, espacio liderado por el Ministerio de Justicia y la Defensoría del Pueblo. Como quedó registrado en los Autos 121 de 2018 y 141 de 2019, la falta de consenso en la definición de estándares e indicadores de vida en reclusión por parte de estas entidades, ha sido objeto de llamados de atención por parte de la Corte Constitucional, que ha tenido que mediar esa relación, a veces tensa, de cara a apurar la definición de estos elementos centrales en el seguimiento del ECI. En particular, en el Auto 141 de 2019 se señaló:

[E]sta Sala Especial observa con preocupación que las entidades que participan en el Comité interdisciplinario no logren llevar a cabo los consensos necesarios para, si quiera, realizar la entrega del cronograma solicitado en el Auto del 23 de enero de 2019. (...) [E]s inaceptable que la desarticulación institucional sea un nuevo bloqueo para su diseño y puesta en marcha. (...) En ese orden de ideas, el consenso esperado es, en realidad, una obligación y el avance de los bastiones de seguimiento no puede producirse al margen de la línea trazada por esta Corporación.

\subsection{Unos remedios judiciales que no atienden la urgencia de la tragedia humanitaria presente}

Una dificultad, manifestada por Ariza (2015), en la estructura de decisiones tipo ECI para afrontar la crisis penitenciaria del país, tiene que ver con que este tipo 
de decisiones, si bien funcionan muy bien para advertir la gravosa vulneración de derechos de una población, no tienen contemplado un abanico de medidas inmediatas que transformen, en el corto plazo, la realidad denunciada. 0, cabría agregar, cuando se incluyen este tipo de medidas inmediatas, las mismas no contemplan las peculiaridades del campo penitenciario que las hacen irrealizables.

En concreto, el tipo de órdenes que suelen acompañar las decisiones de ECI son complejas, esto es, diseñadas en atención a que el problema identificado requiere la participación de diversos actores, desplegando diversas acciones, cada una de las cuales, usualmente, debe estar sincronizada con las demás, y respecto de las que se estima razonable que no pueden cumplirse en el corto plazo ${ }^{20}$. El ejemplo más claro de las órdenes complejas en el ECI de cárceles es la orden tercera de la Sentencia T-388 de $2013^{21}$. Tras un análisis de fondo y muy detallado de la realidad de las prisiones del país en las consideraciones de la providencia, que advertían una violación de derechos humanos sin precedentes al interior de los centros de reclusión, esta orden fue construida como una orden compleja, para ser cumplida de manera progresiva. En efecto, como quiera que el análisis realizado encontró unas debilidades profundas (por no decir, inexistencias) de las políticas criminal y penitenciaria, la Corte se vio motivada a exigir la formulación e implementación de estas políticas, de modo tal que su diseño pudiese garantizar los derechos humanos, a futuro y de manera sostenible, de todas las personas que son privadas de la libertad.

Como se observa, si bien estas órdenes complejas podrían funcionar para convocar a las autoridades concernidas con las políticas públicas defectuosas para que sean revisadas ${ }^{22}$, en tanto su vocación de cumplimiento es progresiva, no materializan los cambios y transformaciones de la política en el plazo inmediato. De

20 La Sentencia hito de la Corte Constitucional que explica la diferencia entre las órdenes simples y las complejas es la T-086 de 2003, del Magistrado Manuel José Cepeda.

21 “Tercero. - ORDENAR al Gobierno Nacional, a través del Ministerio de Justicia y del Derecho y al INPEC que convoque al Consejo Superior de Política Criminal para que continúe tomando las medidas adecuadas y necesarias para superar el estado de cosas inconstitucional penitenciario y carcelario, teniendo en cuenta, de forma preponderante, los parámetros establecidos en el capítulo (8) y el apartado (10.3.) de las consideraciones de la presente sentencia. Para verificar el cumplimiento de esta orden, el Gobierno Nacional, en compañía del Consejo Superior de Política Criminal deberá remitir dos informes a esta Sala de Revisión, así: (i) El primer informe será remitido en dos (2) meses contados a partir de la notificación de la presente sentencia, informando cuál ha sido el cumplimento de las ordenes de aplicación inmediata, en general y particularmente en las seis cárceles que fueron objeto de alguna de las acciones de tutela de la referencia, e igualmente precisar cómo serán aplicadas las reglas de equilibrio y equilibrio decreciente, tal como fueron descritas en la parte motiva de esta sentencia, y las medidas complementarias que se adoptarán para asegurar la correcta implementación de las mismas. (ii) El segundo informe se deberá presentar en dos (2) años contados a partir de la notificación de la presente sentencia, informando cuál ha sido el cumplimiento de las órdenes complejas de realización progresiva, en general y particularmente en las seis (6) cárceles que fueron objeto de alguna de las acciones de tutela de la referencia (...)". Si bien esta orden es la que caracteriza de mejor forma una orden compleja, en la Sentencia T-762 de 2015 también se encuentran varias de estas órdenes.

22 En todo caso, en el apartado 3.1. ya vimos cómo estas órdenes presentan bloqueos institucionales persistentes que les impiden ser materializadas. 
esta forma, se corre el riesgo de dejar en situación de vulnerabilidad de derechos a la población que está afectada en la actualidad.

Para contrarrestar tal situación, para el caso del ECI de cárceles, la Corte Constitucional construyó una cláusula de ajuste, dirigida específicamente a responder a la situación de las personas actualmente privadas de la libertad. Para ello, se ordenó que, indistintamente del avance en la formulación de la política pública, a todo recluso se le deberían garantizar unos derechos de manera "impostergables, de inmediato e imperativo cumplimiento":

(i) el derecho de los reclusos a ser ubicados en locales higiénicos y dignos, (ii) el derecho de los reclusos a contar con instalaciones sanitarias adecuadas a sus necesidades y al decoro mínimo propio de su dignidad humana, (iii) el derecho de los reclusos a recibir ropa digna para su vestido personal, (iv) el derecho de los reclusos a tener una cama individual con su ropa de cama correspondiente en condiciones higiénicas, y $(v)$ el derecho de los reclusos a contar con alimentación y agua potable, suficiente y adecuada. (vi) la adecuada iluminación y ventilación del sitio de reclusión, (vii) la provisión de los implementos necesarios para el debido aseo personal de los presos, (viii) el derecho de los reclusos a practicar, cuando ello sea posible, un ejercicio diariamente al aire libre, (ix) el derecho de los reclusos a ser examinados por médicos a su ingreso al establecimiento y cuando así se requiera, $(x)$ el derecho de los reclusos a recibir atención médica constante y diligente, $(x i)$ la prohibición de las penas corporales y demás penas crueles, inhumanas o degradantes, (xii) el derecho de los reclusos a acceder a material de lectura, y (xiii) los derechos religiosos de los reclusos. (Corte Constitucional, Sentencia T-388 de 2013)

Aun cuando la fórmula parece resultar viable y oportuna, pues genera la expectativa de la satisfacción de los derechos de los reclusos, una mirada detallada a los mismos hace suponer su inviabilidad e ineficacia al menos parcial. En particular, resultaría inviable garantizar de inmediato cumplimiento todos aquellos derechos que están mediados por adecuaciones a la infraestructura física de los centros de reclusión ${ }^{23}$, habida cuenta, entre otros factores, que estas adecuaciones no se pueden realizar de un momento para otro (por el principio de planeación) y su contratación debe respetar las reglas presupuestales (incluyendo la no superación de los topes asignados). Por si fuera poco, algunos de estos derechos resultan de imposible cumplimiento en un contexto de hacinamiento carcelario como el que sufren casi todos los centros de reclusión del país, en el que, por la sobrepoblación, no es posible

23 En particular: el derecho de los reclusos a contar con instalaciones sanitarias adecuadas a sus necesidades; el derecho de los reclusos a tener una cama individual con su ropa de cama correspondiente en condiciones higiénicas; el derecho de los reclusos a contar con agua potable suficiente y adecuada; y la adecuada iluminación y ventilación del sitio de reclusión. 
solventar la posibilidad de que todos los reclusos tengan dispuesto un camastro para dormir, accedan a personal de salud cuando requieran, o cuenten con instalaciones sanitarias suficientes. Dicho en otros términos, la cláusula de ajuste propuesta por la Corte Constitucional no puede materializarse, con lo cual se mantiene en situación de desprotección de derechos a la población privada de la libertad.

Este escenario, entonces, permite advertir que los esfuerzos pretendidos por la Corte para solventar el déficit de derechos de los presos, que sufren en la actualidad unas condiciones de reclusión contrarias al orden constitucional, no son satisfactorios, como quiera que el remedio de inmediata ejecución, esto es, la garantía de unos medios de habitabilidad respetuosos de la dignidad humana en las prisiones, son de imposible cumplimiento con la rapidez que supone la Corte que se deben materializar.

Esta es la encrucijada a la que se encuentran enfrentados los fallos estructurales de ECI de cárceles: sus órdenes complejas y de ejecución progresiva se encuentran obstaculizadas por diversos bloqueos institucionales que no permiten su puesta en marcha, al tiempo que las órdenes de inmediato cumplimiento no se compadecen con la realidad del campo penitenciario, incapaz de proveer los servicios exigidos en los tiempos demandados.

Ante esta situación, bien parece que se requieren otras decisiones, quizás más fuertes, que resuelvan la tragedia humanitaria que día a día se alimenta desde los pasillos de los penales colombianos, atiborrados de cuerpos humanos, pero a donde no llega ningún viso de dignidad humana.

\section{4. ¿Cómo superar la encrucijada?}

Como se vio, las últimas decisiones estructurales tipo ECI que ha proferido la Corte Constitucional para solucionar la crisis de derechos de las personas privadas de la libertad contienen un paquete de órdenes, complejas y de inmediato cumplimiento, cuya efectividad, aquí, se ha puesto en duda.

A partir del marco teórico analizado, con relación a las órdenes complejas persisten una serie de bloqueos institucionales de tipo político, de capacidades y de fallas burocráticas, que ponen en evidencia múltiples resistencias presentes que impedirían que las medidas progresivas, orientadas hacia el fortalecimiento de las políticas criminal y penitenciaria, logren concretarse y muestren mejoras desde el punto de vista de la satisfacción de los derechos de los reclusos.

Por su parte, en atención a las órdenes de inmediato cumplimiento, las mismas se muestran irrealizables, como quiera que lo ordenado por la Corte no tiene en cuenta las falencias actuales del sistema penitenciario que impiden satisfacer, con la prontitud exigida, los derechos vulnerados. 
En vista de tales circunstancias, la pregunta que surge con ocasión a este análisis tiene que ver con cuál o cuáles deben ser las medidas de carácter inmediato que podrían restaurar el déficit de derechos de los reclusos, actualmente sometidos a condiciones de reclusión ignominiosas. Una orden de este estilo puede consistir en exigir el cambio de reclusión intramural a prisión domiciliaria para un número específico de privados de la libertad que apunte a reducir los márgenes del hacinamiento carcelario ${ }^{24}$. Esta medida puede generar el alivio en la vulneración de los derechos de las personas privadas de la libertad que, de lo contrario, tienen que seguir sufriendo la violación de derechos derivada de las condiciones de reclusión de nuestras prisiones en Colombia, mientras se consolidan unas políticas públicas que quizás se materializarán en el futuro.

Esta medida, además de ser una alternativa al encarcelamiento que no expone a la ciudadanía a los "peligros de la excarcelación masiva", pues se mantienen restricciones en la movilidad de los beneficiados, está enmarcada como una opción que la propia Corte ha buscado en sus remedios de tipo moderado ${ }^{25}$. De este modo, la Corte no solo estaría materializando sus exigencias que hasta la fecha han estado construidas a través de órdenes abiertas, sino que evitaría enfrentar los bloqueos institucionales que se han venido manifestando en resistencia de las medidas alternativas al encarcelamiento.

Sobre este último punto, por supuesto puede que se expresen voces en contra de esta medida de excarcelación. Al menos dos oposiciones se pondrían de presente: (i) la "perjudicial" injerencia de la Corte en la adopción de las medidas, siendo que estas son de resorte del legislador o el ejecutivo, y (ii) el argumento sobre "los riesgos que este tipo de decisiones de excarcelación masiva podrían generar para la seguridad ciudadana"26.

Con relación a la primera oposición, sin profundizar en las discusiones en torno a la legitimidad de este tipo de decisiones (para lo cual ya referí otro tipo de literatura académica que escapa al análisis de este texto ${ }^{27}$, cabe mencionar que la Corte podría "moderar" su injerencia si le pidiera al gobierno construir

24 Otras propuestas sobre excarcelación de población privada de la libertad ya han sido presentadas en Colombia. Por ejemplo, Ariza, antes de la expedición de las leyes que le pusieron límite de tiempo a la privación de la libertad en calidad de sindicados (leyes 1760 de 2015 y 1786 de 2016), había propuesto la "excarcelación individual de personas que hayan pasado un tiempo desproporcionado en prisión como sindicados” (Ariza, 2010, p. 91). Además, el Grupo de Estudios Penales de la Universidad EAFIT (2019) también ha señalado, a propósito de la situación de las cárceles del país, que se debe propender por acelerar la concesión de mecanismos alternativos al encarcelamiento, como la detención domiciliaria o la libertad misma.

25 Por medio de la orden 22.8 de la sentencia T-762 de 2015, la Corte Constitucional exigió al Congreso de la República la creación, implementación y/o ejecución de un "sistema amplio de penas y medidas de aseguramiento alternativas a la privación de la libertad" (Corte Constitucional, Sentencia T-762/15).

26 Ver supra nota 9.

27 Ver supra nota 6. 
unas variables a tener en cuenta para escoger a los reclusos beneficiados. Así, los hacedores de políticas públicas podrían construir técnicamente el campo de aplicación de esta medida y se garantizaría que los beneficiados cumplieran ciertas características desde el punto de vista político-criminal.

En cuanto a la segunda oposición, la participación del gobierno y la sociedad civil en la construcción de los criterios para determinar los presos beneficiados de la excarcelación podría también aliviar estas resistencias. Lo anterior, puesto que la construcción técnica de los criterios mitigaría riesgos en torno a la salida de reclusos que de algún modo pudiesen representar un riesgo para la seguridad ciudadana. A su vez, en paralelo, podría disponerse de un apoyo especial por parte de la Policía Nacional ${ }^{28}$ para ampliar la vigilancia a cargo del INPEC de la población receptora del beneficio domiciliario.

Dicho esto, estas consideraciones son apenas puntos de partida para otro debate. Con todo, resulta necesaria la revisión de este tipo de alternativas que centran el remedio judicial en resolver eficazmente el déficit de derechos, antes que en consideraciones que se mantienen gravitando en la discusión por el diseño de unas políticas públicas que aún aguardan por concretarse.

\section{Conclusiones}

Este texto mostró que los fallos estructurales en materia penitenciaria y carcelaria enfrentan una encrucijada. Por un lado, los remedios judiciales enfocados en resolver los asuntos de la política pública más estructurales (aquellos atinentes al diseño de la política criminal o a las gestiones de sus actores principales) se ven enfrentados a múltiples bloqueos que impiden su cumplimiento efectivo. Por el otro lado, tratándose de las medidas de inmediato cumplimiento, se observó que las mismas no pueden materializarse con la rapidez requerida por consideraciones burocráticas y de las particularidades propias del campo penitenciario.

Este análisis apunta a reflexionar sobre este desafío, con el ánimo que se considere probar remedios complementarios mucho más efectivos para lograr conjurar el déficit de derechos. En esa vía, aquí se propone una medida, que no está exenta de polémica y debate, consistente en forzar una decisión excepcional y expedita de recolocación de privados de la libertad del régimen intramural al domiciliario. Aun cuando puedan existir múltiples reparos, esta propuesta debe entenderse como un punto de partida para que sea considerada, analizada y estudiada, dado que la misma está orientada a resolver de forma inmediata una

28 Este tipo de colaboración no es nuevo. Al contrario, está contemplado en el Código Penitenciario y Carcelario (ver artículo 29-F). 
situación gravosa de protección de derechos, en el entretanto las otras medidas ya propuestas por la Corte se decantan en su cumplimiento.

\section{Referencias bibliográficas}

Ariza, L. (2010). Reformando el infierno: los tribunales y la transformación del campo penitenciario en América Latina. En Ariza, L. y Iturralde, M. (eds.), Los muros de la infamia. Prisiones en Colombia y América Latina (pp. 18-108). Bogotá: Universidad de los Andes, Cijus, Ediciones Uniandes.

Ariza, L. (2011). Dados sin números. Un acercamiento al orden social en la Cárcel La Modelo. Revista de Derecho Público, (26), 1-21.

Ariza, L. (2015). Los derechos económicos, sociales y culturales de las personas presas y la intervención de la Corte Constitucional en el sistema penitenciario colombiano. En Bonilla, D. (ed.), Constitucionalismo del Sur Global (pp. 169-206). Bogotá: Siglo del Hombre Editores.

Ariza, L. y Torres, M. (2019). Definiendo el hacinamiento. Estándares normativos y perspectivas judiciales sobre el espacio penitenciario. Revista Estudios SocioJurídicos, 21(2), 227-258.

Carranza, E. (2009). Cárcel y justicia penal en América Latina y el Caribe. Cómo implementar el modelo de derechos y obligaciones de las Naciones Unidas. México: Siglo XXI Editores, Instituto Latinoamericano de las Naciones Unidas para la Prevención del Delito y Tratamiento del Delincuente, Instituto Raoul Wallenberg de Derechos Humanos y Derecho Humanitario.

Cepeda, M. (2007). La ubicación de la Corte Constitucional en el sistema político. En Cepeda, M. J. et al. (eds.), Teoría constitucional y políticas públicas. Bases críticas para una discusión. Bogotá. Universidad Externado de Colombia.

Cita, R. y González, I. (2017). La proporcionalidad de las penas en la legislación penal colombiana. Bogotá: Ministerio de Justicia y del Derecho.

Colombia. Congreso de Colombia. (6 de julio de 2015). Ley 1760. Por medio de la cual se modifica parcialmente la Ley 906 de 2004 en relación con las medidas de aseguramiento privativas de la libertad. Recuperado de https://bibliotecadigital. ccb.org.co/bitstream/handle/11520/14262/LEY\%201760\%20DEL\%2006\%20 DE\%20JULIO\%20DE\%202015.pdf?sequence=1\&isAllowed=y

Colombia. Congreso de Colombia. (1 de julio de 2016). Ley 1786. Por medio de la cual se modifican algunas disposiciones de la Ley 1760 de 2015. Diario Oficial n. $\underline{\mathrm{o}}$ 49.921. Recuperado de http://www.secretariasenado.gov.co/senado/basedoc/ ley_1786_2016.html\#: :text=Las\%20medidas\%20de\%20aseguramiento $\% 20$ privativas\%20de $\% 20$ la $\% 20$ libertad $\% 20$ solo\%20podr\%C3\%A1n,de\%20la\%20 medida\%20de\%20aseguramiento 
Colombia. Congreso de Colombia. (junio 30 de 2017). Ley 1837 de 2017. Por la cual se efectúan unas modificaciones al Presupuesto General de la Nación para la vigencia fiscal de 2017. Diario Oficial n. -50.280 . Recuperado de http://www. secretariasenado.gov.co/senado/basedoc/ley_1837_2017.html

Colombia. Congreso de Colombia. (30 de mayo de 2018). Ley 1896. Por medio de la cual se exceptúa al ministerio del trabajo, al instituto nacional penitenciario y carcelario (INPEC), al Congreso de la República - Cámara de Representantes y Senado de la República, a la Unidad Administrativa Especial de Aeronáutica Civil (Uaeac) y al Departamento Administrativo para la Prosperidad Social (DPS), de lo dispuesto en el artículo 92 de la ley 617 de 2000. Recuperado de https://dapre. presidencia.gov.co/normativa/normativa/LEY\%201896\%20DEL\%2030\%20 DE\%20MAYO\%20DE\%202018.pdf

Colombia. Corte Constitucional. (22 de febrero de 2018). Auto 121/18. [MS. Gloria Stella Ortiz Delgado].

Colombia. Corte Constitucional. (26 de marzo de 2019). Auto 141/19. [MS. Gloria Stella Ortiz Delgado].

Colombia. Corte Constitucional. (28 de abril de 1998). Sentencia T-153/98. [MP Eduardo Cifuentes Muñoz].

Colombia. Corte Constitucional. (6 de febrero de 2003). Sentencia T-086/03. [MS Manuel Cepeda Espinosa].

Colombia. Corte Constitucional. (22 de enero de 2004). Sentencia T-025/04. [MP Manuel José Cepeda Espinosa].

Colombia. Corte Constitucional. (28 de junio de 2013). Sentencia T-388/13. [MP María Victoria Calle Correa].

Colombia. Corte Constitucional. (16 de diciembre de 2015). Sentencia T-762. [MP Gloria Stella Ortiz Delgado].

Colombia. Corte Constitucional. (3 de abril de 2017). Sentencia T-197-17. [MP Luis Guillermo Guerrero Pérez].

Consejo Nacional de Planeación Económica y Social (Conpes). (2000). Documento Conpes 3086. Ampliación de la infraestructura penitenciaria y carcelaria. Recuperado dehttps://colaboracion.dnp.gov.co/CDT/Conpes/Econ\%C3\%B3micos/3086.pdf

Consejo Nacional de Planeación Económica y Social (Conpes). (2004). Documento Conpes 3277. Estrategia para la expansión de la oferta nacional de cupos penitenciarios y carcelarios. Recuperado de https://colaboracion.dnp.gov.co/CDT/ Conpes/Econ\%C3\%B3micos/3277.pdf

Consejo Nacional de Planeación Económica y Social (Conpes). (2006). Documento Conpes 3412. Estrategia para la expansión de la oferta nacional de cupos penitenciarios y carcelarios - Seguimiento del Conpes 3277. Recuperado de https://colaboracion. dnp.gov.co/CDT/Conpes/Econ\%C3\%B3micos/3412.pdf 
Consejo Nacional de Planeación Económica y Social (Conpes). (2009). Documento Conpes 3575. Estrategia para la expansión de la oferta nacional de cupos penitenciarios y carcelarios - Seguimiento a los Conpes 3277 de marzo 2004 y 3412 de marzo de 2006. Recuperado de https://colaboracion.dnp.gov.co/CDT/Conpes/ Econ\%C3\%B3micos/3575.pdf

Consejo Superior de Política Criminal. (2016). Concepto 16.12. Estudio al borrador del proyecto de ley "Fortalecimiento de la política criminal y penitenciaria en Colombia" - por medio de la cual se modifica la ley 1709 de 2014, algunas disposiciones del Código Penal, Código de Procedimiento Penal, Código Penitenciario y Carcelario, Código de Infancia y Adolescencia, la Ley 1121 de 2006 y se dictan otras disposiciones. Recuperado de http://www.politicacriminal.gov.co/Portals/0/Conceptos\%20 CSPC/Conceptos\%202016/12.\%20CSPC\%20Propuesta\%20de\%20Reforma\%20 Ley\%201709.pdf?ver=2017-10-12-091128-000\&timestamp=1510895078955

Consejo Superior de Política Criminal. (2017). Concepto 17.2017. Estudio del Consejo Superior de Política Criminal al Proyecto de Ley número 014 de 2017 Senado, "por medio de la cual se fortalece la política criminal y penitenciaria en Colombia y se dictan otras disposiciones". Recuperado de http://www.politicacriminal.gov.co/Portals/0/Conceptos\%20CSPC/Conceptos\%202017/17.\%20Concepto\%20CSPC_PL\%20014\%20 17.pdf?ver=2017-10-12-091758-000\&timestamp=1510895284285

Contraloría General de la República. (2017a). Informe auditoría de cumplimiento. Fondo nacional de salud de las personas privadas de la libertad. Vigencia 2016 -Junio 302017. Recuperado de https://www.contraloria.gov.co/documents/20181/750567/5-+F0 NDO+NACIONAL+DE+SALUD+DE+LAS+PERSONAS+PRIVADAS+DE+LA+LIBERTAD pdf/d4e8e216-3c1a-4f49-9d74-5daeeaa3683c?version=1.0.

Contraloría General de la República. (2017b). Informe auditoría de cumplimiento. Suministro de bienes, prestación de servicios, infraestructura y el apoyo logístico y administrativo para la población privada de la libertad. Vigencia 1 de enero de 2016 - 30 de junio 2017. Recuperado de https://www.contraloria.gov.co/ documents /20181/750567/4-+Informe+USPEC+Suministro+de+Bienes. pdf/0270874d-f4c2-4459-9068-66f071fca9d4?version=1.0.

Contraloría General de la República. (2018). Informe de auditoría financiera. Unidad de Servicios Penitenciarios y Carcelarios - USPEC. Vigencia 2017. Recuperado de https://www.uspec.gov.co/wp-content/uploads/2018/11/Informe-FinalAuditoria-Financiera-Vigencia-2017.pdf.

Contraloría General de la República. (2019a). Informe auditoría de cumplimiento contratación en infraestructura, alimentación y salud. Instituto Nacional Penitenciario y Carcelario y Unidad de Servicios Penitenciarios y Carcelarios. 2018 a 30 de junio de 2019. Recuperado de https://www.contraloria.gov.co/documents/20181/1406069/Nro.+025+Informe+Auditor\%C3\%ADa+Cumplimien to+USPEC+INPEC.pdf/b5ac0778-0aa9-4679-99f8-f5e6742a7a0f?version=1.0

Contraloría General de la República. (2019b). Informe de auditoría financiera. Unidad de Servicios Penitenciarios y Carcelarios - USPEC. Vigencia 2018. Recuperado 
de https://www.uspec.gov.co/wp-content/uploads/2018/11/Informe-FinalAuditoria-Financiera-Vigencia-2018.pdf.

Contraloría General de la República. (2020a). Informe de auditoría independiente. Auditoría financiera. Unidad de Servicios Penitenciarios y Carcelarios - USPEC. Vigencia 2019. Recuperado de https://www.uspec.gov.co/wp-content/uploads/2018/11/ Informe-Final-Auditoria-Financiera-CGR-Vigencia-2019.pdf

Contraloría General de la República. (2020b). En la vigencia 2019, la USPEC dejó de ejecutar \$44.922 millones de su apropiación presupuestal para inversión. [Comunicado de prensa No. 80].Recuperado de https://www.contraloria.gov.co/ contraloria/sala-de-prensa/boletines-de-prensa/boletines-de-prensa-2020/-/ asset_publisher/9IOzepbPkrRW/content/en-la-vigencia-2019-la-uspec-dejode-ejecutar-44-922-millones-de-su-apropiacion-presupuestal-para-inversion

Defensoría del Pueblo. (2004). Análisis sobre el actual hacinamiento carcelario y penitenciario en Colombia - 2003. Recuperado de https://www.defensoria.gov.co/ attachment/76/An\%C3\%A1lisis\%20sobre\%20el\%20actual\%20hacinamiento $\% 20$ carcelario\%20y\%20penitenciario $\% 20$ en\%20Colombia.pdf.

Defensoría del Pueblo. (2015). Resolución Defensorial 066 de 2015. Crisis en la prestación de servicios de salud en los establecimientos penitenciarios y carcelarios de los departamentos de Antioquiay Meta. Recuperado de http://www.defensoria.gov.co/es/public/ resoluciones/3341/Resoluci\%C3\%B3n-Defensorial-066-de-2015-Defensorial.htm

Garland, D. (2012). La cultura del control. Crimen y orden social en la sociedad contemporánea. Barcelona: Editorial Gedisa.

Grupo de Estudios Penales de la Universidad EAFIT (2019). Editorial. Revista Nuevo Foro Penal, 15(92), 7-20.

Grupo líder de seguimiento. (2016). Primer informe semestral de seguimiento a la sentencia T-762 del 2015. Bogotá. Recuperado de http://www.politicacriminal. gov.co/Portals/0/Primer-Informe-Grupo-Lider-de-Seguimiento-Sentencia-T762-de-2015-ilovepdf-compressed-1-100.pdf?ver=2016-12-09-172038-980 y http://www.politicacriminal.gov.co/Portals/0/Primer-Informe-Grupo-Liderde-Seguimiento-Sentencia-T-762-de-2015-ilovepdf-compressed-101-213. pdf?ver=2016-12-09-172117-637

Grupo líder de seguimiento. (2017). Segundo informe semestral de seguimiento a la sentencia T-762 del 2015. Bogotá. Recuperado de http://www.politicacriminal.gov.co/ Portals/0/documento/SegInforCC9junio17.pdf?ver=2017-06-23-140709-443

Henao Pérez, J. C. (2013). El juez constitucional: un actor de las políticas públicas. Revista de Economía Institucional, 15(29), 67-102.

Instituto Nacional Penitenciario y Carcelario (INPEC). (2020). Series históricas mayo de 2020. Recuperado de http://www.inpec.gov.co/portal/page/portal/Inpec/ Institucion/Estad\%EDsticas/Estadisticas/Estad\%EDsticas

Iturralde, M. (2007). La sociología del castigo de David Garland: el control del crimen en las sociedades modernas tardías. En Garland, D. (ed.), Crimen y castigo en la 
modernidad tardía (pp.19-122). Bogotá: Siglo del Hombre Editores, Universidad de los Andes, Pontificia Universidad Javeriana.

Iturralde, M. (2010a). Castigo, liberalismo autoritario y justicia penal de excepción. Bogotá: Siglo del Hombre Editores, Universidad de los Andes, Pontificia Universidad Javeriana.

Iturralde, M. (2010b). Prisiones y castigo en Colombia: la construcción de un orden social excluyente. En Ariza, L. J. y Iturralde, M. (eds.), Los muros de la infamia (pp. 110-194). Bogotá: Universidad de los Andes, Facultad de Derecho, Cijus, Ediciones Uniandes.

Ministerio de Justicia y del Derecho (MinJusticia). (2020). Respuesta al cuestionario del Auto proferido el 3 de junio de 2020, sobre medidas de contingencia para enfrentar el COVID-19 en centros carcelarios. Recuperado de http://www.politicacriminal.gov.co/Portals/0/autos/Respuesta_Auto_03_de_junio_2020/MJDOFI20-0020005.pdf.

Moscoso Sepúlveda, S. (2017). Sistema penitenciario y carcelario. Intervención de la Corte Constitucional en la política pública penal. Bogotá: Grupo Editorial Ibáñez.

Noticiero CM\& [CM\& la noticia]. (2017). No se puede hacer una feria de rebaja de penas: Fiscal General. [Archivo de video]. Recuperado de https://www.youtube.com/ watch?v=nHY4hm6oqTM

Noticias RPTV [Noticias RPTV]. (2016). Excarcelaciones masivas afectan la seguridad ciudadana - Noticias RPTV. [Archivo de video]. Recuperado de https://www. youtube.com/watch?v=5UR8G-laqsU

Ramírez, H., Gómez, W., Medina, A., Farfán, M. y Moncada, R. (2019). Análisis del desarrollo jurisprudencial del estado de cosas inconstitucional en el sistema penitenciario y carcelario en Colombia (1998-2015). En Huertas, O., Manrique, F. y Benítez, C. (eds.), Análisis del estado de cosas inconstitucional en el sistema penitenciario y carcelario en Colombia. Propuestas para el Estado social de derecho (pp. 57-79). Bogotá: Universidad Nacional de Colombia, Universidad Pedagógica y Tecnológica de Colombia.

Rodríguez Garavito, C. y Rodríguez Franco, D. (2010). Cortes y cambio social: cómo la Corte Constitucional transformó el desplazamiento forzado en Colombia. Bogotá: Centro de Estudios de Derecho, Justicia y Sociedad, Dejusticia.

Rodríguez Garavito, C. y Rodríguez Franco, D. (2015). Juicio a la exclusión. El impacto de los tribunales sobre los derechos sociales en el Sur Global. Buenos Aires: Siglo Veintiuno Editores.

Travis, J. (2000). But they all come back: rethinking prisoner reentry. Sentencing and Corrections, 7, 1-11.

Wacquant, L. (2010). Las cárceles de la miseria. Buenos Aires: Manantial.

World Prison Brief. (2017). World Prison Brief data. Recuperado de http://www.prisonstudies.org/map/south-america

Zaffaroni, E. (2013). La cuestión criminal. Buenos Aires: Planeta. 